\section{Drug Shortages in Health Care Institutions: Perspectives in Early 2013}

The year 2012 was perceived by many stakeholders as the worst ever with respect to drug shortages in Canada. Following receipt of a warning letter ${ }^{1}$ from the US Food and Drug Administration in November 2011, Novartis International AG, on behalf of its Canadian operations at Sandoz Canada, issued a customer letter ${ }^{2}$ in mid-February 2012 indicating that the company's production capacity would be significantly reduced for some time, that manufacturing would be suspended for many products, and that many other products would be available only in limited quantities through a national allocation process. Hospital pharmacists were active during the crisis in attempting to limit the impact of the resulting drug shortages. As a result of this crisis, unprecedented mobilization of stakeholders was observed throughout the country, and purchasing agents and professional organizations collaborated to form task forces at both the national and the provincial level. In addition, 2 bodies published key reports: in April 2012, the Ordre des pharmaciens du Québec (Quebec Society of Pharmacists) published a set of recommendations on interruptions in the drug supply, ${ }^{3}$ and in June 2012, the House of Commons Standing Committee on Health published its own report on the Canadian drug supply. ${ }^{4}$

Nearly 2 years ago, in February 2011, the Pharmacy Practice Research Unit of the Centre hospitalier universitaire Sainte-Justine launched a pair of open-access websites that present the current status of drug shortages in Canada (see www.fridaypm.ca [English] and www.vendredipm.ca [French]). The websites are updated daily by the drug manufacturers that are under contract to SigmaSanté (the group purchasing agent for hospitals in the Montréal and Laval areas and the Eastern Townships of Quebec), as dictated by a specific clause in the group purchasing agreement. In addition, the website is updated weekly by a major Canadian wholesaler (McKesson Canada) and on the basis of voluntary reporting by hospital pharmacists.

Our research unit has been gathering data on drug shortages since 2006.5 Here, we provide an update on the situation for the period from September 1, 2011, to August 30, 2012. A total of 1081 drug shortages were reported over this 12-month period, which represents a $152 \%$ increase from the 429 drug shortages reported for a similar 12-month period in 2010-2011. ${ }^{6}$ Before 2010, the annual number of drug shortages was 493 in 2006, 400 in 2007, 441 in 2008, and 679 in 2009.5

The average duration of drug shortages has also increased considerably, with a mean ( \pm standard deviation) of $141 \pm 116$ days (range 1-775 days) over the 12-month period from September 2011 to August 2012, compared with $103 \pm 85$ days (range 8-363 days) for the 12-month period in 2010-2011 and $108 \pm 130$ days (range 5-1623 days) over the period
2006-2010. ${ }^{6}$ In the most recent period of analysis (2011-2012), parenteral formulations represented 33\% of the total number of drug shortages and $37 \%$ of the total number of days of drug shortages.

The number of manufacturers involved in drug shortages increased from 41 in $2010-2011^{5}$ to 58 manufacturers in 2011-2012. The number totalled 70 over the period 2006-2010. ${ }^{6}$ Most of the drug shortages in 2011-2012 involved generic drug manufacturers, which represented $67 \%$ of the total number of drug shortages and $74 \%$ of the total number of drug-shortage days. The main manufacturers involved were, in decreasing order of proportion of total number of shortages, Teva (18\%), Apotex (16\%), Sandoz (14\%), Hospira (8\%), Pharmascience (6\%), and Baxter (5\%).

Most therapeutic classes were affected by shortages in 2011-2012. In decreasing order of the number of drug shortages, drug classes affected were central nervous system agents (AHFS drug classification 28:00), accounting for 22\% of affected products; anti-infective agents (08:00), 14\%; cardiovascular drugs (24:00), 14\%; skin and mucous membrane agents (84:00), 8\%; gastrointestinal drugs (56:00), 7\%; hormones and synthetic substitutes (68:00), 7\%; electrolytic, caloric, and water balance agents (40:00), 6\%; antineoplastic drugs (10:00), 4\%; and all other classes (18\%).

This update indicates an important increase in drug shortages for the period from September 2011 to August 2012, with 4 generic drug manufacturers accounting for more than $50 \%$ of the total number of drug shortages. Although shortages of parental drugs represented only a third of all shortages, lack of supply of these drugs can have greater consequences (relative to other types of drugs) on patient safety in acute care and hospital settings, especially when multiple agents are produced by a single manufacturer.

In the southwestern region of Quebec, drug manufacturers have been expected to self-report shortages to the "Friday PM" website since late 2011. Although it would have been more accurate to use the manufacturer's self-reported data, we used only data from the wholesaler for the analysis reported above, because these data conform with the methodology that our research group has used since 2004. More specifically, we identified $42 \%$ under-reporting of drug shortages by the wholesaler relative to self-reporting by the manufacturers. This gap is largely explained by shortages reported by Apotex but not by the wholesaler. Such under-reporting by the wholesaler may be explained by the existence of sufficient inventory levels of some drugs, the availability of other formulations from one or more other generic drug manufacturers, and other in-house factors. Certainly, the situation in 2011-2012 was worse than what we have reported previously. ${ }^{5,6}$ Further analysis will be conducted in 2012-2013, using self-reported data from drug manufacturers, once a full year of such data are available. 
Strong action is required to encourage federal legislative changes and to reverse this negative trend in the Canadian pharmaceutical market. Meanwhile, we will continue to monitor the situation.

\section{References}

1. Inspections, compliance, enforcement, and criminal investigations: Novartis International AG 11/18/11 [warning letter]. Silver Spring (MD): Food and Drug Administration (US); 2011 Nov 18 [cited 2012 Sep 20]. Available from: www.fda.gov/ICECI/EnforcementActions/WarningLetters/ucm281843.htm

2. Lettre aux clients (15-16 février). Boucherville (QC): Sandoz Canada Inc.; 2012 Feb 15 [cited 2012 Sep 20]. Available from: www.sandoz.ca/site/ fr/products/inventaire/customerletter/letter1.shtml?licensecode=catalogue

3. Recommandations du comité sur les ruptures d'approvisionnement en médicaments. Les ruptures d'approvisionnement en médicaments. Montréal (QC): Comité de travail sur les ruptures d'approvisionnement en médicaments; 2012 Apr [cited 2012 Sep 19]. Available from: www.opq.org/cms/Media/1233_38_ fr-CA_0_Rapport_ruptures_approvisionnement.pdf

4. Drug supply in Canada: a multistakeholder responsibility. Ottawa (ON): House of Commons Standing Committee on Health; 2012 Jun [cited 2012 Dec 20]. Available from: www.parl.gc.ca/content/hoc/Committee/411/HESA/Reports/ RP5640047/hesarp09/hesarp09-e.pdf

5. Bussières JF, Chiveri A, Lebel D. Perspective sur les ruptures d'approvisionnement de médicaments en établissement de santé de 2006 à 2010. Can J Hosp Pharm. 2011;64(6):426-35.

6. Ottino G, Lebel D, Bussières JF. Drug shortages in health care institutions: perspectives in early 2012 [letter]. Can J Hosp Pharm. 2012;65(2):151-2.

\section{Isabelle Barthélémy}

Research Assistant

Denis Lebel, BPharm, MSc, FCSHP

Assistant Director

Jean-François Bussières, BPharm, MSc, FCSHP

Director

Pharmacy Practice Research Unit

Centre hospitalier universitaire Sainte-Justine

Montréal, Quebec
Isabelle Barthélémy is also a DPharm intern at Université Claude Bernard Lyon 1, Villeurbanne, France. Denis Lebel is also Assistant Director, Pharmaceutical Care, Teaching, and Research, with the Pharmacy Department of Centre hospitalier universitaire (CHU) Sainte-Justine. Jean-François Bussières is also Director of the Pharmacy Department of CHU Sainte-Justine and Professor in the Faculty of Pharmacy, Université de Montréal.

Competing interests: None declared.

\section{Availability of Drug Samples in Hospitals: Opportunity or Threat?}

In Canada, the Food and Drug Act allows the distribution of drug samples to physicians, dentists, and pharmacists. ${ }^{1}$ Most provincial regulatory authorities do not prohibit the distribution of such samples in health care settings. ${ }^{2}$ However, drug samples are perceived differently by different health care stakeholders. ${ }^{2}$ In particular, the use of drug samples may bypass the optimal druguse process in hospitals and retail pharmacies. ${ }^{3-5}$

The objective of this cross-sectional observational study was to compare the number of drug samples available in outpatient clinics in a mother-child university hospital centre in the province of Quebec in 2007, 2009, and 2012. In the study hospital, drug samples were not allowed in patient wards but were tolerated in outpatient clinics. Drug samples were monitored every 6 months by pharmacy staff, who made unannounced visits to the clinics. In addition to biannual monitoring, extensive audits were conducted periodically over 1 - to 2-week periods. During the first extensive audit, in 2007, the

Table 1. Profile of Drug Samples in a Mother-Child Teaching Hospital in 2007, 2009, and 2012

\begin{tabular}{|c|c|c|c|c|c|c|}
\hline \multirow[b]{2}{*}{ Outpatient Clinic* } & \multicolumn{2}{|c|}{2007} & \multicolumn{2}{|c|}{2009} & \multicolumn{2}{|c|}{2012} \\
\hline & $\begin{array}{c}\text { No. of } \\
\text { Samples }\end{array}$ & $\begin{array}{c}\text { Doses per } \\
\text { Patient } \\
\text { Visit }\end{array}$ & $\begin{array}{c}\text { No. of } \\
\text { Samples }\end{array}$ & $\begin{array}{c}\text { Doses per } \\
\text { Patient } \\
\text { Visit }\end{array}$ & $\begin{array}{c}\text { No. of } \\
\text { Samples }\end{array}$ & $\begin{array}{c}\text { Doses per } \\
\text { Patient } \\
\text { Visit }\end{array}$ \\
\hline Pulmonology & 564 & 5.16 & 484 & 0.88 & 189 & 0.73 \\
\hline Obstetrics and gynecology $(n=5)$ & 1157 & 0.52 & 308 & 0.12 & 239 & 0.17 \\
\hline Pediatrics $(n=2)$ & 961 & 1.26 & 867 & 0.67 & 785 & 0.57 \\
\hline Dermatology $(n=3)$ & 2398 & 1.49 & 3525 & 5.53 & 3563 & 6.06 \\
\hline Otolaryngology & 6056 & 0.64 & 1316 & 0.79 & 989 & 0.52 \\
\hline Gastroenterology & 251 & 0.45 & 480 & 0.23 & 249 & 0.66 \\
\hline Dialysis & 202 & 1.61 & 0 & 0.00 & 0 & 0.00 \\
\hline Endocrinology & 19 & 0.94 & 33 & 0.04 & 2 & 0.08 \\
\hline Adolescent medicine & 179 & 0.64 & 36 & 0.06 & 116 & 1.02 \\
\hline Emergency $(n=2)$ & 311 & 0.02 & 44 & 0.01 & 0 & 0.00 \\
\hline Allergy & 200 & 0.41 & 0 & 0.00 & 245 & 2.10 \\
\hline Ophthalmology & 858 & 0.09 & 212 & 0.26 & 268 & 0.05 \\
\hline Urology & 78 & 0.25 & 23 & 0.03 & 46 & 0.09 \\
\hline Neurology & 170 & 0.12 & 33 & 0.03 & 30 & 0.04 \\
\hline Dentistry $(n=2)$ & 329 & 0.12 & 63 & 0.03 & 268 & 0.17 \\
\hline Growth and development & 152 & 0.17 & 273 & 0.45 & 0 & 0.00 \\
\hline Diabetes & 214 & 0.13 & 205 & 0.35 & 0 & 0.00 \\
\hline Orthopedics & 71 & 0.01 & 28 & 0.01 & 0 & 0.00 \\
\hline Daycare & 33 & 0.02 & 19 & 0.02 & 0 & 0.00 \\
\hline Neonatology $(n=2)$ & 4 & 0.03 & 0 & 0.00 & 0 & 0.00 \\
\hline Renal transplantation & 14 & 0.02 & 131 & 0.71 & 0 & 0.00 \\
\hline Total $(n=31)$ & 14221 & 0.40 & 8080 & 0.38 & 6989 & 0.41 \\
\hline
\end{tabular}

*Data were collected from one location within each outpatient clinic, except where indicated otherwise. 